\title{
Co-creation as a Success Factor in the Development of Constructive Customer-Focused Dialogues
}

DOI: 10.12776/QIP.V24I2.1442

\author{
Anna Mårtensson, Pernilla Ingelsson, Ingela Bäckström
}

Received: 2020-04-02 Accepted: 2020-05-25 Published: 2020-07-31

\begin{abstract}
Purpose: The purpose of this study is to describe the process of co-creating a dialogue model that aims to increase citizen value in a municipality organisation. In addition, the purpose is to present the results from the development process and to evaluate the chosen dialogue model.

Methodology/Approach: A dialogue model was developed through a cocreation process with a series of workshops, discussions and interactive tasks. The whole process was carried out in three steps. In the first step, the success factors of a constructive dialogue based on citizen value were identified. In the second step, several dialogue models were developed, tested and evaluated, and one dialogue model was chosen. In the third step, the chosen dialogue model was evaluated.
\end{abstract}

Findings: An evaluation of a real-life use of the dialogue model supports the finding that the process delivers a dialogue model that enables the required prerequisites for constructive dialogues: for example, the opportunity to prepare, to create structured and transparent documentation, and to enable a holistic view of the dialogue model. A co-creation that involved co-workers contributed to developing a dialogue model that could be adapted to the co-workers' own context.

Research Limitation/implication: This study is conducted in a single organization, hence no generalizable conclusions can be made.

Originality/Value of paper: Using a co-creative process when developing and realising a dialogue model enhances the possibility of adapting the model to an organisation's specific context.

Category: Case study

Keywords: co-creation; customer focus; dialogue model; A3; holistic view 


\section{INTRODUCTION}

When organisations try to understand customers and stakeholders, the organisations find the customer and stakeholder needs and expectations to be the most challenging to understand (Westher, 2018). After understanding customer needs and expectations, the organisation must be managed to fulfil these. This process demands knowledge about customers and the capacity to develop organisations in line with customer demands. Customers' needs and situations or contexts must be understood to create customer value (Kristensson, Gustafsson, and Witell, 2014). Creating customer value is considered the most valuable aspect of organisations (Oh, 1999) and is considered the source of other values in an organisation (Hammer, 1996). Notably, customers can be found in all organisations, even though some organisations do not refer to them as customers (Bäckström, 2009).

Quality management is defined by Flynn, Schroeder and Sakakibara (1994) as 'an approach to achieving and sustaining high quality output', which supports both a customer focus by understanding value creation from the customer's perspective and by creating the values, methods and tools to develop organisations in a customer-oriented direction (Bergman and Klefsjö, 2010). A focus on customers aligns with the values of the cornerstone model that form the basis of quality management: having committed management, focusing on processes, improving continuously, basing decisions on facts, and enabling everyone to be committed (Bergman and Klefsjö, 2010). The value 'focus on customers' is considered the purpose of quality management and is claimed to contribute to knowledge and understanding of customer value creation. The relationship between internal and external customers is that internal customersemployees-need to be satisfied to deliver an outcome in line with the satisfaction of external customers (Dahlgaard, Kristensen and Kanji, 2002). The satisfaction of customers can be equated to achieving customer value, which Carlsson and Wilmot (2006) explain as giving value to internal customers and making it possible to maximise the value of external customers.

Organisational values are fundamental for organisational culture, which is unique for each organisation (Campbell, 2004). Organisational culture is connected to organisational performance in two ways: culture energises employees by appealing to their higher ideals and undefined values, and it shapes and coordinates behaviours and decisions (Chatman and Eunyoung Cha, 2003; Grönfeldt and Strother, 2006). According to Wu, Zhang and Schroeder (2011), quality management culture is important because it influences how quality practices are customised to achieve higher performance outcomes. Ingelsson, Eriksson and Lilja (2012) describe a developed model that connects organisational values with a strategy for selecting people within the organisation who support the organisation's values. The model is inspired by Hellsten and Klefsjö (2000) and has the overall aim of increasing internal and external customer satisfaction with a reduced amount of resources. Managers and employees are the organisational resources that affect the organisational culture 
and thereby the performance outcome. According to Bäckström (2009) and Lagrosen, Bäckström and Wiklund (2012), the 'leadership commitment' and 'participation of everybody' values are important for supporting sustainable health among co-workers when quality management is practised. Employees also have knowledge of the unique context, which is a crucial factor of success in quality management work (Asif et al., 2009).

By tapping into employees' capacity, their existing knowledge base can be used to reach newly developed products, services or processes (Carmeli, Gelbard and Reitner-Palmon, 2013). Other ways to become more innovative are to involve other actors in society, such as industry, academia, suppliers and customers (Gassmann and Enkel, 2004). Lee, Hwang and Choi (2012) express that innovation in the public sector is driven to improve service performance and add value through public benefit. Different definitions exist for the terms of development, change and innovation. Within each context, a label needs to be placed on what is being done. In this paper, the term development is used to mean taking steps forward to increase value for customers.

\subsection{Co-creation for Development}

Co-operation has a long history in the field of quality management. At the beginning of the $20^{\text {th }}$ century, Frederick Winslow Taylor described the importance of co-operation between employers and employees for achieving expected outcomes to reduce waste on the production line (Taylor, 1998). In this section, the function of co-operation is understood as the dissemination of information that has been developed through-among other things-the cornerstone model, which is used to describe the focus on customers and their involvement and the stimulation of customer engagement (Bergman and Klefsjö, 2010). Research has identified the need to find models for co-operation within organisations regarding, for example, the avoidance of misunderstandings and increase in knowledge transfer. Cronemyr (2007) demonstrate positive results in these areas through the method of 'knowledge overlapping seminars', that is, seminars that aim to achieve common concepts, fewer misunderstandings, better quality, and more satisfied customers.

A more elaborated form of co-operation is co-creation. Co-creation can be viewed as a collaborative process used in business through which customers and organisations interact to identify needs and benefits from services and the goals (Leavy, 2012; Lee, Olson and Trimi, 2012). When applied in the context of increased citizen value, co-creation can be viewed as engendering participation and transferring knowledge. Lee, Olson and Trimi (2012) point to the significance of co-creation in assisting organisations with establishing shared values.

Co-creation can be carried out in many different ways. Dialogues present a process of increasing knowledge and highlighting a subject from different angles. According to Hamilton and Pinnegar (2015), a dialogue is defined as 'a process 
of coming-to-know through which meaning is made and on the strength of which we develop assertions for action or understanding' and contains 'inquiry, critique, evidence, reflection, and response'. The interest in dialogues has increased in organisations with public relations and has played a key role in organisations that want to involve stakeholders from a broader perspective (Gutiérrez-García, Recalde and Piñera-Camacho, 2015). In addition to encompassing a broader stakeholder perspective, dialogues also support a management culture that is able to meet the various expectations of a wide range of individuals and groups (ibid.).

In appreciative inquiry (AI), appreciative interviews are one-on-one dialogues that focus on asking questions and sharing stories about highpoint experiences and valuable activities-in a positive spirit (Cooperrider and Whitney, 2005). The interviews generate results that assist organisations in growing in the requested direction (ibid.). AI is a theory, an approach and a mindset that leads to creativity and organisational learning (Watkins and Cooperrider, 2000). AI builds a vibrant, high-performing and customer-focused culture by systematically discovering what gives life to an organisation and when the organisation is the most effective and capable in economic, ecological and social terms (Cooperrider and Whitney, 2005). The culture of AI is a culture that Whitney and Trosten-Bloom (2010) describe as working with the strengths of the persons involved.

\subsection{Increased Customer Benefit: Contextual Challenges}

Municipalities in Sweden are required to follow the mandatory directive issued by the government and have the opportunity to engage in voluntary assignments. According to Statens författningssamling 2017:725 (SFS, 2017), a member of a municipality is defined as follows.

$5 \S$ 'A member of a municipality is the one who is registered in the municipality, owns real estate in the municipality or is to pay municipal tax there'.

'A member of a municipality is also a citizen of one of the Member States of the European Union (Union citizen) who resides in the municipality but who, according to § 5, second paragraph, the Public Registration Act (1991)(481), shall not be registered there'.

The task of a municipality is to carry out assignments for its citizens. Laws, regulations and guidelines control the assignments, which can be complemented by local regulations such as e.g politically targeted investments. The political organisation of a municipality is governed by the national law SFS 2017:725 Kommunallag (SFS, 2017); however, each municipality is free to create a structure and working methods for performing its internal tasks (Sveriges Kommuner och Landsting, 2019). A municipality is a complex system with many stakeholders that needs to be dynamic, adapt to needs and interact with many other systems in society. The constituent parts of a municipality need to be coordinated and followed upon within the municipal structure; they then form the basis for continued work. 
Municipalities are part of the public sector, and funding is based on taxes. According to Lee, Hwang and Choi (2012), drivers in the public sector are increasing customer value for target groups and reducing costs for taxpayers. Moore (1995) clarifies that public value is understood as the achievement of preferred outcomes by using public resources in the most effective manner available. Result-based management is a common practice in the public sector and occurs at all levels, from local, regional, and national to supranational (Van Thiel and Leeuw, 2002). Researchers Van Thiel and Leeuw (2002) further reflect on the relations between performance measurement indicators, analyses and the room for interpretation in different respects. Moreover, the authors describe that most products in the public sector are intangible. Performance indicators should reflect quality and reliability rather than 'hard' product attributes: 'Public services are not only about efficiency and effectiveness but also about justice, fairness, equity, and accountability' (ibid.).

This case study focuses on co-creation as an important factor in the development process to increase citizen value when the management in a municipality analyses and evaluates performance. Committed co-workers and managers are a prerequisite for organisational performance outcomes. If the values are also shared and if appropriate methodologies and tools are applied, the conditions for a successful result are improved. Because all organisations are unique, the adoption of organisational values needs to be customised. Achieving this cocreation can be a way to make co-workers committed. Moreover, according to Seddon and Caulkin (2007), adopting a new way of thinking through action is easier than inducing new and counterintuitive ways of acting by thinking about the ways. Co-creation can also be a way to induce a breakthrough during changes in an organisation. Senge (1999) describes that people do not resist change but resist being changed.

The purpose of this paper is to describe the process of co-creating a dialogue model that aims to increase citizen value in a municipality organisation. In addition, the purpose is to present the results from the development process and evaluation of the chosen dialogue model.

\section{METHODOLOGY}

The municipality approached Mid Sweden University to obtain input after it identified a need to improve its ways of working to achieve a higher performance. The municipality is located in the middle of Sweden and serves approximately 100,000 citizens. In the autumn of 2017, the council established guidelines for a new model for controlling and managing the municipality that increased the focus on performance-based management. In short, these guidelines imply that control measures must be based on quality analyses of actual, achieved results among citizens/users and that the municipality desires to achieve better performance-based management through simplification, clarity and quality analyses. The municipality wanted to find a way of working that would focus on 
creating citizen value and identifying dialogues about the results as an important tool.

A joint pre-study project started on 01 September 2018 and ended on 01 March 2019 for the purposes of developing a new method of working with performance analysis and dialogues. The project team had five members-two from the municipality and three from the University. The work was divided into two parts; Part 1 was to develop the dialogue model and consisted of two steps (Step One and Step Two), and Part 2 consisted of one step (Step Three) was to evaluate the use of the developed dialogue model.

To obtain an understanding of the current situation in the municipality, the project team started Part 1 by conducting interviews with the leaders, both elected representatives and officials. The project team created an interview guide that focused on the respondents describing the existing management model and their experiences using it. The project team members from the municipality chose a total of six relevant respondents. Members from the University conducted the interviews over Skype or the telephone. During the interviews, notes were taken, which were subsequently sent to each respondent for verification. In two cases, the notes were corrected.

In parallel to the interviews, the development of the dialogue model was initiated. In Step One, input for developing a prototype model for the dialogue was collected. This was done through a workshop, with the purpose of identifying the success factors from fruitful and constructive dialogues based on the effects on and the results of citizens-a total of 30 officials participated. Based on the results from the interviews with the leaders and the first workshop, Step Two in the development process started with a number of dialogue model prototypes were developed. These dialogue models were then tested and evaluated in a second workshop, where 21 officials and seven elected representatives participated. The results from the second workshop led to the decision to choose one dialogue model. Both workshops were facilitated by the researchers on the project.

Part 2 included testing and evaluating the final dialogue model. In the first round, the dialogue model was used in a total of six dialogues between the councillor and the municipal administration from different boards. Subsequently, six participating persons-two elected representatives and four officials-answered a written evaluation. In addition to the written evaluation, the project members from the municipality conducted an oral evaluation with nine participants, one elected representative and eight officials, who were partly the same participants who answered the written evaluation. During the oral evaluation, notes were taken by the project members from the municipality. Thus far, the dialogue model was used twice with the same configuration as in the first meeting, and after each round, an oral evaluation was performed by the project members from the municipality. 
Even starting the project required that all of its parts were to be completed through the co-operation of the team members from the municipality and the University, because the co-operations was a prerequisite for the funding of the project. Throughout the project, dialogues continuously occurred within the project team to conduct analyses and evaluations and to make decisions.

\section{RESULTS}

This section is divided into two parts. Part 1 presents the development process of the dialogue model (Step One) and the testing of the prototypes (Step Two). Part 2 presents the evaluation of the dialogue model used in real life for the first time and a summary of the model's continued use (Step Three).

\subsection{Part 1 - Development and Testing of the Model for Dialogue}

According to the plan, two workshops with officials and elected representatives from the municipality were conducted. The purpose was to obtain as good input as possible for the actual performance-based dialogue models as well as anchoring the work in the organisation.

\section{Step One}

For the first workshop, the invitation was sent to the administration managers and the financial manager and to the internal quality network. The purpose of this workshop was to identify the success factors based on fruitful and constructive dialogues on the effects on and results of citizens. The purpose was also to identify concrete proposals for how the success factors could be realised. The identified success factors and proposals for the concrete implementation of the factors are presented in Table 1. The workshop started with one-on-one dialogues, and participants used an interview guide inspired by appreciative inquiry with questions that aimed to find the strengths and success factors. When an interview was completed, the pair of participants that performed the interview met another pair. Together, their mission was to find and agree on the five most inspiring success factors from the interviews and write them down on Post-it Notes. Each group of two pairs presented their results from the practice to the entire group. Subsequently, all Post-it Notes were rearranged to find patterns and make groups of related Post-its. The new Post-it groups received a descriptive heading. The next exercise required the participants to choose a heading and start a group task to generate an idea around the question: What concrete ideas do I want to send to the work group that is developing the prototypes? During this exercise, the participants had the opportunity to change groups and contribute to several headings. 
Table 1 - Identified Success Factors and Proposals for the Concrete Implementation of the Factors from the First Workshop in the Development Process

\begin{tabular}{|c|c|c|c|c|}
\hline Category & Prerequisites & Approach & $\begin{array}{l}\text { Structure and } \\
\text { process }\end{array}$ & Goal/Why? \\
\hline \multirow{12}{*}{$\begin{array}{l}\text { Underlying } \\
\text { concepts }\end{array}$} & Self-awareness & Be curious & Documentation & Common challenges \\
\hline & Commitment & Be open & Moderator & Clear purpose \\
\hline & $\begin{array}{l}\text { Why-Creates } \\
\text { commitment }\end{array}$ & Be listening & Facilitator & Solution-oriented \\
\hline & Participation & Listen & Time for preparation & Common goal \\
\hline & Understanding & $\begin{array}{l}\text { Listen-understand } \\
\text { the context, be } \\
\text { humble }\end{array}$ & $\begin{array}{l}\text { Enough time for } \\
\text { dialogue }\end{array}$ & Clarity \\
\hline & $\begin{array}{c}\text { Understanding of } \\
\text { different } \\
\text { perspectives }\end{array}$ & $\begin{array}{l}\text { Think outside the } \\
\text { box-have courage }\end{array}$ & $\begin{array}{l}\text { Appropriate } \\
\text { "vocabulary" }\end{array}$ & $\begin{array}{l}\text { Who? Participant, } \\
\text { target group, } \\
\text { customer }\end{array}$ \\
\hline & & Be respectful & Common basis & \\
\hline & & & Structure & \\
\hline & & & Systematics & \\
\hline & & & $\begin{array}{l}\text { Using tools for } \\
\text { common } \\
\text { understanding }\end{array}$ & \\
\hline & & & $\begin{array}{l}\text { Solid preparation and } \\
\text { perseverance }\end{array}$ & \\
\hline & & & Meeting in person & \\
\hline
\end{tabular}

The results from the first workshop, together with the results from the interviews, became the input for the project team's work to generate a number of model prototypes for a new way of carrying out performance-based dialogues. In total, three different prototypes for performance-based dialogues were generated and tested in two different forms during workshop two. The prototypes tested in workshop two were as follows: traditional meeting with an agenda, structured $\mathrm{A} 3^{1}$ and a dialogue canvas ${ }^{2}$. The two different forms in which each dialogue model was tested were traditional questions and questions with strength-based ${ }^{3}$ elements. In addition to the dialogue models, three fictitious cases were

\footnotetext{
${ }^{1}$ A3 refers to the internationally agreed-upon paper size, which is viewed as a common, logical way of thinking; this design can be adapted to different situations. A3 connects a problem with cases, goals, and proposed measures to reach the target and provide the resources to measure success (Shook, 2011).

${ }^{2}$ In this case, the dialogue canvas is the A1 paper format with pre-printed fields with questions and a space to write down documentation. All participants are encouraged to write on the canvas during the dialogue.

${ }^{3}$ The strength-based questions are inspired by the appreciative inquiry approach (AI); see for instance Whitney and Trosten-Bloom (2010).
} 
developed to focus on the process and not on real-life challenges. The three fictitious cases were Elementary School, Home Care and Origo Park. A general description of the development of Part 1 is visualised in Figure 1.

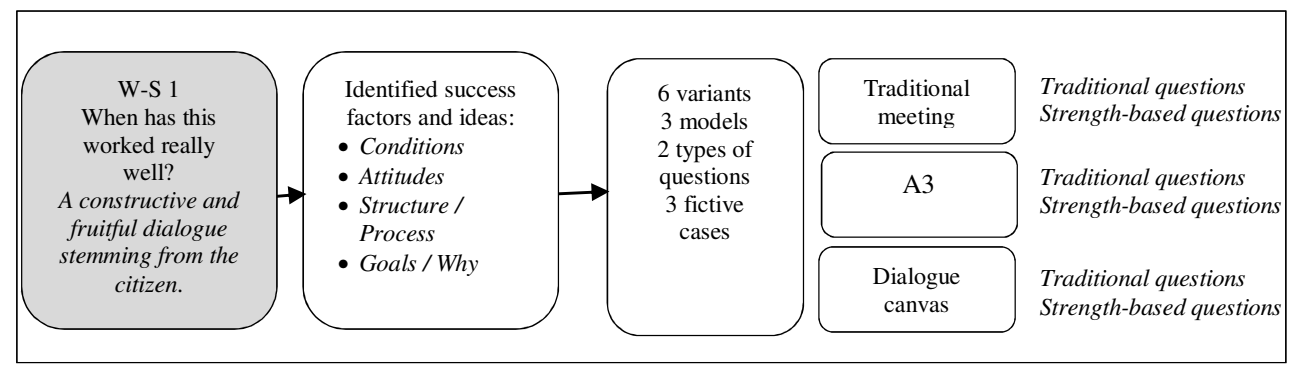

Figure 1 - General Description of Step One in the Overall Development of the Model for Performance-based Dialogues

\section{Step Two}

Before the second workshop, the invitation was sent to everyone who participated or wanted to participate in the first workshop and to elected representatives on the municipal board finance committees (ordinary and replacement). On this occasion, the participants were grouped, and each group had the opportunity to test two prototypes during the workshop. The different prototypes were tested according to a schedule, see Table 2. Before starting a test, each group received information and instructions from the observer, and if the prototype contained roles, the roles were distributed amongst the participants in the group. Each test was timed and had a specific time limit. After each test, participants answered an evaluation form with questions on whether everyone had the opportunity to speak and be listened to, how they experienced the documentation, whether a supporting structure existed, and what worked well and what worked less well.

Table 2 - Schedule of Tests of the Different Performance-based Dialogue Prototypes

\begin{tabular}{|c|c|c|c|c|c|c|}
\hline $\begin{array}{l}\text { Type of } \\
\text { dialogue model }\end{array}$ & A3 (am) & A3 (pm) & $\begin{array}{c}\text { Dialogue } \\
\text { canvas (am) }\end{array}$ & $\begin{array}{c}\text { Dialogue } \\
\text { canvas }(\mathrm{pm})\end{array}$ & $\begin{array}{l}\text { Agenda } \\
\text { (am) }\end{array}$ & $\begin{array}{l}\text { Agenda } \\
(\mathrm{pm})\end{array}$ \\
\hline Observer & \multicolumn{2}{|c|}{ Researcher A } & \multicolumn{2}{|c|}{ Researcher B } & \multicolumn{2}{|c|}{ Researcher C } \\
\hline Case & $\begin{array}{c}\text { Elementary } \\
\text { school }\end{array}$ & $\begin{array}{c}\text { Elementary } \\
\text { school }\end{array}$ & Home care & Home care & $\begin{array}{l}\text { Origo } \\
\text { Park }\end{array}$ & $\begin{array}{l}\text { Origo } \\
\text { Park }\end{array}$ \\
\hline $\begin{array}{l}\text { Type of } \\
\text { questions }\end{array}$ & Ordinary & $\begin{array}{l}\text { Strenght- } \\
\text { based }\end{array}$ & Ordinary & $\begin{array}{l}\text { Strenght- } \\
\text { based }\end{array}$ & Ordinary & $\begin{array}{l}\text { Strenght- } \\
\text { based }\end{array}$ \\
\hline Group & 1 & 3 & 2 & 1 & 3 & 2 \\
\hline
\end{tabular}


When all prototypes were tested, the groups evaluated each prototype from four different perspectives: citizen, co-worker, process and business, and financials. The group had to split $100 \%$ of their meeting time, as they experienced how they focused on the parts. The participants also had to fill in the 'other' opportunity. At the end of the workshop, the participants worked in pairs and brainstormed around three themes: 'Needs to be!', 'Definitely not!', and 'Maybe!'. This session aimed to collect the participants' overall perceptions of the prototypes.

After workshop 2, all evaluations were analysed, which resulted in a dialogue model that starts with sending out preparatory materials to participants. The dialogue model also consists of meeting rules, a documentation template, a clear division of roles, and a focus on citizen values and having a holistic view. The prototype that best matched all of these criteria was an A3 model with strengthbased inspired questions. Subsequently, this dialogue model was jointly discussed with the project group, the chairperson of the municipal board and the municipal director. The output from the discussion led to a further adaptation of the dialogue model before testing the model in real life.

\subsection{Part 2 - Evaluation of the Performance-based Dialogue Model}

\section{Step Three}

At this time, the developed model for performance-based dialogues was ready to be tested in real life. In this part, the dialogue model was evaluated through both written and oral evaluations with the participants.

The results from the written evaluation indicate that, in general, all respondents were positive about using the dialogue model. Four respondents found that the dialogue model contributed to an increased understanding and clarification of expectations and results. One respondent stated that it was difficult to compare because he or she was new to the role. Another respondent expressed that the large size of the business made it difficult to state that the dialogue model fully contributed to understanding and clarifying expectations and results; however, the dialogue model was better than the previous way of working. All respondents thought that all participants had the opportunity to speak and that they participated and were committed during the meeting. Five respondents also thought that all participants' opinions and views were taken into account, and one respondent did not answer that question. The opinions on the documentation were divided. Three respondents were positive, one respondent found it to be too short but thought that the documentation could still support the organisation, and two respondents did not like the format, or they had not seen it yet. The allocated meeting time was not a prioritised issue, according to the respondents.

In addition to these questions, the respondents submitted comments on what 'worked well' and 'what worked less well'. Regarding 'what worked well', there were some examples of comments regarding the area: a good structure that supported speaking about continuous improvement, good atmosphere, suitable group size, good discussion about both business and financial results, and a good 
way of discussing quality and business. On the list of 'what worked less well' were the following: too much time was set aside, the documentation that was sent out before the meeting needed to be developed in terms of scope and content, there was a risk that the participants were too careful and nice during the meeting, and these kinds of dialogues are also needed between different administration parts.

The outcome from the oral evaluations with participants after the performancebased dialogues were completed was also analysed according to 'what worked well' and 'what worked less well'. Additionally, a third field, 'other', was added. Regarding 'what worked well' the comments were as follows: a good atmosphere during the dialogues and the A3 had a good structure-for instance, everyone around the table was able to talk-and the focus of the questions. Respondents also highlighted that 'what worked well' were the outcomes from the dialogue and that the focus was not only on the financials. One respondent expressed that participating in the performance-based dialogue was a learning experience. Regarding 'what worked less well', there were comments about the atmosphere, which was too kind and not challenging enough. The 'what worked less well' comments also included a dialogue model that was too structured, a request for more open conversations and the need to further develop preparatory material. Regarding 'other', there were reflections on the feedback, such as the following: 'What did the municipal board, municipal director and financial manager think?' 'What happens to the assignments that ended up at the municipal executive's office?' 'Why did the HR director who participated not participate?' Issues listed as 'other' included the number of participants who had influence, which was not too many and not too few.

During 2019, the dialogue model was used two more times in the same configuration. The purpose was the same, but the theme was adjusted to meet the internal business needs. The second time the dialogue model was used, the theme was economic deviation, and the third time the theme addressed next year's operational planning. The dialogue model was supplemented with an added point during the actual meeting; each meeting started with a review and follow-up of the decisions and measures that were the output of the previous meeting. Until this point, the evaluations showed that the outcome from using the dialogue model was appreciated by the participants. The highest management had increased knowledge about the organisation, and constructive actions were taken. The format of the model, to set aside time for recurring meetings, was highlighted. This way of working also contributed to continuity and provided a clearer way of addressing the assignments of the administrations and committees. A fourth meeting using the dialogue model is already booked, which has as its theme the results of the next year, and the plan is to continue with four meetings on a yearly basis. During 2020, the meetings will also be extended to include the municipal corporations. 


\section{ANALYSIS AND DISCUSSION}

The purpose of this paper was to describe the process of co-creating a dialogue model that aimed to increase citizen value in a municipality organisation. In addition, the purpose was to present the results from the development process and an evaluation of the chosen dialogue model.

A dialogue model was developed through a co-creation process with the intention of the model being a useful methodology for the municipality board and management to use in their work on performance-based management. Cocreation was carried out in more than one way. The first way was to create conditions for the development process that enabled elected representatives, managers and co-workers to participate. The second way to engender a cooperation that became a co-creation among the members on the project team, who were from the municipality and the University.

According to Leavy (2012) and Lee, Olson and Trimi (2012), interaction that occurs through co-creation can create prerequisites for identifying the needs and benefits from services and goals. During the entire development process, the focus on citizen value was the main goal. In the first workshop, the focus was on identifying the success factors from fruitful and constructive dialogues that were based on the effects on and results of the citizen, which can be concretely implemented in quality management through the value 'focus on customers' from the cornerstone model of Bergman and Klefsjö (2010). In the second workshop, during prototype testing, the participants contributed to the development of the dialogue model by evaluating the citizen value when using each prototype. The participants also contributed by categorising different topics from the tests into 'Needs to be!', 'Definitely not!', and 'Maybe!' categories. The evaluations from using the dialogue model in real life also supported the concept that citizen value was considered. In the evaluation form, the fact that the participants in the dialogue were able to talk about quality and business was seen as a benefit, given that both are connected to creating value for the citizen. The dialogues indicated that the participants were able to focus on questions in the developed dialogue model, the A3, which were oriented towards value creation.

Co-creation has also been shown as fruitful in relation to the quality management values presented in Bergman and Klefsjö (2010): 'let everybody be committed' and 'management commitment'. By inviting co-workers and managers to the workshops and allowing them to contribute knowledge and comments, conditions for commitment were created. Inviting and involving committed coworkers followed the model proposed by Ingelsson, Eriksson and Lilja (2012), in which the step of involving employees who support the organisation's values added to the chain between valuation and choosing the right methodologies and tools to fulfil the desired result.

By implementing a new model for control and management with an increased focus on performance-based management in the municipality, the council aimed for changes in ways of acting. Seddon and Caulkin (2007) express that it is easier 
to adopt a new way of thinking through action than by thinking about the new and unknown. The way that the dialogue model was developed can be seen as an example of acting to find new and counterintuitive ways of acting. Co-creation through the involvement of co-workers during the development of the dialogue model can facilitate change: as Senge (1999) describes, people do not resist change but resist being changed.

The developed dialogue model was used in dialogues by the municipality's highest management and by different administration parts of the organisation. The evaluations performed after the real-life test indicate that the dialogue model created conditions in the organisation for listening to each other and that the model increased the understanding of different needs by clarifying expectations and results. The developed dialogue model was found to have similarities with the method of 'knowledge overlapping seminars' presented by Cronemyr (2007), since the evaluations presented results in line with creating a common view and increased knowledge among the participants.

The municipality has a defined goal for its development of performance-based management; however, whether the municipality has a shared organisational culture and shared values among co-workers is unknown. By involving coworkers in the development process of the methods and tools, the prerequisites were created to allow their values to appear in the method that was developed. In the next step, the co-workers' participation may have effects on organisational performance, because the values are connected to organisational culture, which is connected to organisational performance (Chatman and Eunyoung Cha, 2003; Grönfeldt and Strother, 2006). Another possible effect of allowing co-workers to participate in the development process is that it could create conditions for health among them (Bäckström, 2009; Lagrosen, Bäckström and Wiklund, 2012). Asif et al. (2009) suggest that co-workers should be involved when quality management is implemented and that they should assist in the adoption of the unique context. This organisation has not expressed that they are implementing quality management, but the desired results are in line with quality management outcomes. However, it can be assumed that the co-workers have made it possible to develop the dialogue model for adaptation to their own context.

Gutiérrez-García, Recalde and Piñera-Camacho (2015) describe two perspectives on having dialogues in the public sector: creating an opportunity to involve stakeholders and supporting a management culture. On the management side, dialogues create conditions for meeting the various expectations of a wide range of individuals and groups. In the presented development process and the adaptation of the dialogue model, only one of these sides can be said to have been present, creating conditions for meeting the various expectations of a wide range of individuals and groups. This situation exists because at this stage, the dialogue model has been implemented only in the internal process of performance-based management but with a customer focus. The evaluations indicate that conditions to satisfy and create value for the internal customers occurred in the development process and by using the dialogue model. Internal 
customer value creation increases the conditions that maximise the value for external customers (Carlsson and Wilmot, 2006).

\section{CONCLUSION}

The development process in this study can be used in other situations and organisations. The process is not limited to creating dialogue models in performance-based management because the co-creation process can be used for other key topics. The results from this study indicate that the co-creation process is suitable when an organisation wants to involve co-workers to improve their knowledge, contextualise a specific issue and develop methodologies for internal use. In this study, an internally developed dialogue model fulfilled the desired goal of finding a way of working that focuses on creating citizen value.

The results indicate that questions raised in the developed dialogue model (A3) helped the participants focus on value creation. Therefore, such a model can guide the dialogue towards desired areas and create a dialogue whereby the participants listen to each other more. The dialogue model also created a new way of acting for management. The results also indicate that the developed dialogue model created an opportunity for the municipality board to adopt a holistic view.

Areas for future research include following up on whether the dialogue model supports the long-term view of the agreed-upon conclusion and the activities in each performed dialogue and verifying the effects on created value for citizens from the citizens' perspective. The dialogue model may also need to be further developed so that all participants experience its use as effective, given the feedback on the time spent, and so that they can feel free to express themselves regardless of their opinions and challenge the prevailing norms and structures.

\section{REFERENCES}

Asif, M., Joost de Bruijn, E., Douglas, A. and Fisscher, O., 2009. Why quality management programs fail: A strategic and operations management perspective. International Journal of Quality \& Reliability Management, [e-journal] 26(8), pp.778-794. DOI: 10.1108/02656710910984165.

Bäckström, I., 2009. On the relationship between sustainable health and quality management: leadership and organizational behaviours from Swedish organizations. PhD. Östersund, Mid Sweden University.

Bergman, B. and Klefsjö, B., 2010. Quality: From customer needs to customer satisfaction. Lund: Studentlitteratur.

Campbell, C.R., 2004. Longitudinal Study of One Organization's Culture: Do Values Endure?. American Journal of Business, [e-journal] 19(2), pp.41-52. DOI: $10.1108 / 19355181200400011$. 
Carlson, C.R. and Wilmot, W.W., 2006. Innovation the Five Disciplines for Creating what Customers Want. New York: Crown Publishing Group.

Carmeli, A., Gelbard, R. and Reitner-Palmon, R., 2013. Problem-solvning capacity, and creative performance: The importance of knowledge sharing. Human Resource Management, 52(1), pp.95-122.

Chatman, J.A. and Eunyoung Cha, S., 2003. Leading by Leveraging Culture. California Management Review, 45(4), pp.20-34.

Cooperrider, D. and Whitney, D., 2005. Appreciative Inquiry: A positive revolution in change. San Francisco: Berrett-Koehler Publishers.

Cronemyr, P., 2007. Six Sigma Management: action research with some contributions to theories and methods. PhD. Chalmers University of Technology. Available at: <http://urn.kb.se/resolve?urn=urn:nbn:se:liu:diva-100856> [Accessed 08 July 2020].

Dahlgaard, J., Kristensen, K. and Kanji, G., 2002. Fundamentals of Total Quality Management. Cheltenham: Nelson Thornes.

Flynn, B.B., Schroeder, R.G. and Sakakibara, S., 1994. A framework for quality management research and an associated measurement instrument. Journal of Operations management, 11(4), pp.339-366.

Gassmann, O. and Enkel, E., 2004. Towards a theory of open innovation: Three core process archetypes. In: RADMA (Research and Developlent Management Association), Proceedings of the R\&D Management Conference. Lissabon.

Grönfeldt, S. and Strother, J., 2006. Service leadership: the quest for competitive advantage. Thousand Oaks, Calif.: SAGE Publications.

Gutiérrez-García, E., Recalde, M. and Piñera-Camacho, A., 2015. Reinventing the wheel? A comparative overview of the concept of dialogue. Public Relations Review, [e-journal] 41(5), pp.744-753. DOI: 10.1016/j.pubrev.2015.06.006.

Hamilton, M.L. and Pinnegar, S., 2015. Knowing, Becoming, doing as Teacher Educators: Identity, Intimate Scholarship, Inquiry. Emerald Publishing Group Limited.

Hammer, M., 1996. Beyond reengineering: how the process-centred organization is changing our work and our lives. New York: Harper business.

Hellsten, U. and Klefsjö, B., 2000. TQM as a management system consisting of values, techniques and tools. The TQM Magazine, [e-journal] 12(4), pp.238-244. DOI: $10.1108 / 09544780010325822$.

Ingelsson, P., Eriksson, M. and Lilja, J., 2012. Can selecting the right values help TQM implementation? A case study about organisational homogeneity at the Walt Disney Company. Total Quality Management, [e-journal] 23(1), pp.1-11. DOI: $10.1080 / 14783363.2011 .637801$.

Kristensson, P., Gustafsson, A. and Witell, L., 2014. Tjänsteinnovation. Lund: Studentlitteratur. 
Lagrosen, Y., Bäckström, I. and Wiklund, H., 2012. Approach for measuring health-related quality management. The TQM Journal, [e-journal] 24(1), pp.5971. DOI: $10.1108 / 17542731211191221$.

Leavy, B., 2012. Collaborative innovation as the new imperative - design thinking, value co-creation and the power if "pull". Strategy \& Leadership, [ejournal] 40(2), pp.25-34. DOI: 10.1108/10878571211209323.

Lee, S., Hwang, T. and Choi, D., 2012. Open innovation in the public sector of leading countries. Management Decision, [e-journal] 50(1), pp.147-162. DOI: $10.1108 / 00251741211194921$.

Lee, S., Olson, D. and Trimi, S., 2012. Co-innovation: Convergenomics, collaboration, and co-creation for organizational values. Management Decision, [e-journal] 50(5), pp.817-831. DOI: 10.1108/00251741211227528.

Moore, M.H., 1995. Creating public value: Strategic Management in Government. Cambridge Massachusetts: Harvard University Press.

Oh, H., 1999. Service quality, customer satisfaction, and customer value: A holistic perspective. International Journal of Hospitality Management, [ejournal] 18(1), pp.67-82. DOI: 10.1016/S0278-4319(98)00047-4.

Seddon, J. and Caulkin, S., 2007. Systems Thinking, Lean Production and Action Learning. Action Learning: Research and Practice, 4(1), pp.9-24. DOI: 10.1080/14767330701231438.

Senge, P., 1999. The dance of change: The challenge to sustaining momentum in learning organizations. New York: Doubleday.

SFS (Statens Författningssamling), 2017. Kommunallag (2017:725). Finansdepartementet K: SFS. Available at: $<$ https://www.riksdagen.se/sv/dokument-lagar/dokument/svenskforfattningssamling/kommunallag-2017725_sfs-2017-725> [Accessed 20 May 2019].

Shook, J., 2011. Lean management: med hjälp av A3-analyses. Malmö: Liber.

Sveriges Kommuner och Landsting, 2019. Så styrs en kommun. Bruxelles: Swedish Association of Local Authorities and Regions. Available at: $<$ https://skl.se/demokratiledningstyrning/politiskstyrningfortroendevalda/kommu naltsjalvstyresastyrskommunenochregionen/sastyrskommunen.735.html> [Accessed 20 May 2019].

Taylor, F.W., 1998. The principles of scientific management. Canada, Toronto: General publishing company Ltd.

Van Thiel, S. and Leeuw, F., 2002. The performance paradox in the public sector. Public Performance and Management Review, [e-journal] 25(3), pp.267281. DOI: 10.1080/15309576.2002.11643661.

Watkins, J.M. and Cooperrider, D., 2000. Appreciative inquiry: a transformative paradigm. OD Practitioner, 32(1), pp.6-12. 
Westher, M., 2018. Organisationers främsta utmaningar: En studie med fem års horisont. Göteborg: SIQ - Institutet för Kvalitetsutveckling.

Whitney, D. and Trosten-Bloom A., 2010. The power of Appreciative Inquiry. San Francisco: Berrett-Koehler Publishers.

Wu, S., Zhang, D. and Schroeder, R., 2011. Customization of quality practices: the impact of quality culture. International Journal of Quality \& Reliability Management, [e-journal] 28(3), pp.263-279. DOI: 10.1108/02656711111109883.

\section{ABOUT AUTHORS}

Anna Mårtensson - (A.M.) Mid Sweden University, Östersund, Sweden, Department of Quality Technology and Management, Ph.D. Student in Quality Management, e-mail: anna.martensson@miun.se, Author's ORCID: 0000-00018609-6290.

Pernilla Ingelsson - (P.I.) Mid Sweden University, Östersund, Sweden, Department of Quality Technology and Management, Assoc. Prof. in Quality Management, e-mail: pernilla.ingelsson@miun.se, Author's ORCID: 0000-00015610-2944.

Ingela Bäckström - (I.B.) Mid Sweden University, Östersund, Sweden, Department of Quality Technology and Management, Prof. in Quality Management, e-mail: ingela.backstrom@miun.se, Author's ORCID: 0000-00017621-2649.

\section{AUTHOR CONTRIBUTIONS}

A.M. - writing-original draft; I.B. - project administration; A.M., P.I. visualization; I.B., P.I. - funding acquisition; A.M., P.I., I.B. - conceptualization, methodology, validation, formal analysis, investigation, writing-review and editing.

\section{CONFLICTS OF INTEREST}

The authors declare no conflict of interest. The funders had no role in the design of the study; in the collection, analyses, or interpretation of data; in the writing of the manuscript, or in the decision to publish the results.

(C) 2020 by the authors. Submitted for possible open access publication under the terms and conditions of the Creative Commons Attribution (CC-BY) license (http://creativecommons.org/licenses/by/4.0/). 